\title{
Modeling and Optimization for Production of Rice Husk Activated Carbon and Adsorption of Phenol
}

\author{
Y. S. Mohammad, ${ }^{1}$ E. M. Shaibu-Imodagbe, ${ }^{2}$ S. B. Igboro, ${ }^{1}$ A. Giwa, ${ }^{3}$ and C. A. Okuofu ${ }^{1}$ \\ ${ }^{1}$ Department of Water Resources and Environmental Engineering, ABU, Zaria, Nigeria \\ ${ }^{2}$ Samaru College of Agriculture, Division of Agricultural Colleges, ABU, Zaria, Nigeria \\ ${ }^{3}$ Department of Textile Science and Technology, ABU, Zaria, Nigeria \\ Correspondence should be addressed to Y. S. Mohammad; yahsaymoh@yahoo.co.uk
}

Received 8 August 2014; Revised 6 December 2014; Accepted 8 December 2014; Published 24 December 2014

Academic Editor: Sreekanth Pannala

Copyright (C) 2014 Y. S. Mohammad et al. This is an open access article distributed under the Creative Commons Attribution License, which permits unrestricted use, distribution, and reproduction in any medium, provided the original work is properly cited.

\begin{abstract}
Modeling of adsorption process establishes mathematical relationship between the interacting process variables and process optimization is important in determining the values of factors for which the response is at maximum. In this paper, response surface methodology was employed for the modeling and optimization of adsorption of phenol onto rice husk activated carbon. Among the action variables considered are activated carbon pretreatment temperature, adsorbent dosage, and initial concentration of phenol, while the response variables are removal efficiency and adsorption capacity. Regression analysis was used to analyze the models developed. The outcome of this research showed that $99.79 \%$ and $99.81 \%$ of the variations in removal efficiency and adsorption capacity, respectively, are attributed to the three process variables considered, that is, pretreatment temperature, adsorbent dosage, and initial phenol concentration. Therefore, the models can be used to predict the interaction of the process variables. Optimization tests showed that the optimum operating conditions for the adsorption process occurred at initial solute concentration of $40.61 \mathrm{mg} / \mathrm{L}$, pretreatment temperature of $441.46^{\circ} \mathrm{C}$, adsorbent dosage $4 \mathrm{~g}$, adsorption capacity of $0.9595 \mathrm{mg} / \mathrm{g}$, and removal efficiency of $97.16 \%$. These optimum operating conditions were experimentally validated.
\end{abstract}

\section{Introduction}

The increase in industrial, agricultural, and domestic activities has led to the discharge of large amounts of wastewater containing toxic pollutants. The growing awareness of the adverse effects of the presence of these water pollutants has led to increased strict regulation of water pollution, hence making the treatment of wastewater generated from industrial activities a high priority [1]. Phenols are among the most common water pollutants that can cause hazards including health hazard which may lead to death. Amongst hydrocarbons present in refinery wastewater, phenol is one of the main dissolved components and it is also one of the difficult hydrocarbons to degrade biologically $[2,3]$. Consequently, pollution control and management have evolved many technologies for the treatment of wastewater $[4,5]$. These technologies and methodologies which differ in their performance and effectiveness include coagulation, filtration, ion exchange, sedimentation, solvent extraction, adsorption, electrodialysis, chemical oxidation, disinfection, chemical precipitation, and membrane separation [6,7]. Among the various available technologies for water pollution control, adsorption process is considered relatively better because of its convenience, ease in operation and simplicity of design [8-10]. The process can remove different types of pollutants due to the availability of wide range of adsorbents especially activated carbon which make it to have a wider applicability in water pollution control [7, 11-13]. Rice husk is an agricultural waste that is readily available as a by-product of rice processing but requires pretreatment to produce activated carbon for better performance as an adsorbent.

Response Surface Methodology (RSM) had been known as a collection of mathematical and statistical techniques for modeling and analyzing problems in which a response of interest is influenced by several variables. Basically, it had been used in multivariate experimental design, statistical 
modeling and process optimization $[14,15]$. Thus process optimization was observed to be important in determining the values of factors for which the response is at maximum. The application of statistical experimental design techniques in adsorption process was found to result in reduced process variability combined with the requirement of less resources (time, reagents and experimental work) $[16,17]$. It had been reported that RSM has several classes of designs, among which are; central composite design, box-behnken design and three-level factorial design being the most widely used and the experimental data required are dependent on the chosen design $[18,19]$. There is little or no information on the optimization of carbonization temperature for the production of rice husk activated carbon for phenol adsorption using response surface methodology. In addition, the usual approach to modeling and optimization has been on either the process variable for the production of activated carbon or that of the batch adsorption process. This paper, however, highlights a novel approach involving the simultaneous modeling and optimization of process variables for the production of rice husk activated carbon and batch adsorption of phenol using response surface methodology.

\section{Methods}

2.1. Production of Activated Carbon. The natural precursor used in the preparation of adsorbent was rice husk which was collected from National Cereal Research Institute, Badeggi. When collected from NCRI Rice Mill, the rice husk was washed with distilled water to remove dirt and surface impurity, then oven-dried at $100^{\circ} \mathrm{C}$ for $24 \mathrm{~h}$ in accordance with the procedure of Kudaybergenov et al. [20]. In the thermal pretreatment, rice husk was placed on a ceramic flat surface, charged into a furnace and heated to a temperature of $300^{\circ} \mathrm{C}$ at a heating rate of $20-25^{\circ} \mathrm{C} / \mathrm{min}$ and residence time of $1 \mathrm{~h}$. The charred residue was collected and cooled at room temperature. The procedure above was repeated for $400^{\circ} \mathrm{C}$ and $500^{\circ} \mathrm{C}$. The thermal pretreated rice husks were labeled RH300, RH400 and RH500. In the chemical pretreatment, each of the carbonized rice husk (charred residue) was activated with $1 \mathrm{M} \mathrm{H}_{3} \mathrm{PO}_{4}$ for $3 \mathrm{~h}$ at impregnation ratio of $2: 1$ (volume $\mathrm{mL}$ of acid/mass $\mathrm{g}$ of rice husk) and later ovendried overnight at $200^{\circ} \mathrm{C}$ to ensure proper drying [21, 22]. The material was then removed from the oven, cooled for $2 \mathrm{~h}$ and then washed with distilled water to bring the $\mathrm{pH}$ to 7.0 and again oven-dried overnight at $100^{\circ} \mathrm{C}[21]$.

2.2. Preliminary Batch Experiment. In the preliminary Batch Adsorption experiment, $2 \mathrm{~g}$ of the pretreated adsorbent was added to $100 \mathrm{~mL}$ of standard solution of phenol with initial concentration of 10,30 , and $50 \mathrm{mg} / \mathrm{L}$ in $250 \mathrm{~mL}$ conical flask. The mixture in the flask was placed on magnetic stirrer at $150 \mathrm{rpm}[23,24]$ for $90 \mathrm{~min}$ at ambient temperature. Using a $5 \mathrm{~mL}$ syringe, samples were withdrawn at predetermined time interval $(90 \mathrm{~min})$ and centrifuged at $3000 \mathrm{rpm}$ for $20 \mathrm{~min}$. The supernatant solution was collected from the centrifuge by decantation and filtered using a micro filter attached to a $5 \mathrm{~mL}$ syringe. The procedure above was repeated for 3 and
$4 \mathrm{~g}$ of pretreated adsorbents. The analysis of phenol in each sample filtrate was carried out using UV spectrophotometer set at wave length of $270 \mathrm{~nm}$.

2.3. Determination of Adsorption Capacities and Removal Efficiency. Adsorption capacity $q_{e}$ at equilibrium was determined using the equation $[25,26]$ :

$$
q_{e}=\frac{\left(C_{o}-C_{t}\right) V}{m}
$$

Adsorption removal efficiency was determined using the equation [27-29]:

$$
\mathrm{RE}=\frac{\left(C_{o}-C_{e}\right)}{C_{o}} \times 100,
$$

where $q_{e}=$ adsorption capacity at equilibrium (mg/g), $C_{o}=$ initial concentration of solute $(\mathrm{mg} / \mathrm{L}), C_{e}=$ equilibrium concentration of solute $(\mathrm{mg} / \mathrm{L}), V=$ volume of solution $(\mathrm{L})$, $m=$ mass of activated carbon used $(\mathrm{g})$, and $\mathrm{RE}=$ removal efficiency (\%).

\subsection{Modeling and Optimization}

2.4.1. Experimental Design. The Central Composite Design (CCD) was applied in this work to study the interaction of variables involved in the preparation of rice husk activated carbon as well as batch adsorption process of phenol using the activated carbon prepared. The CCD is widely used for modeling and optimization and it requires only a minimum number of experiments. Generally, the CCD consists of three kinds of runs; they are factorial runs $\left(2^{n}\right)$, axial runs $(2 n)$ and center runs $\left(n_{c}\right)[30,31]$. This design consist of a $2^{n}$ factorial (coded to the usual \pm 1 notation) augmented by $2 n$ axial points $( \pm \alpha, 0,0),(0, \pm \alpha, 0),(0,0, \pm \alpha)$, and $n_{c}$ center points $(0,0,0)[1,32]$, where $\alpha$ is the distance of the axial point from the center [33]. The center points are used to determine the experimental error and reproducibility of the data $[34,35]$ and the axial points are chosen such that they allow rotatability which ensures that the variance of the model prediction is constant at all points equidistant from the design center [36]. Therefore, according to Abbas [37] and Arulkumar et al., [38], the number of experimental runs required is given by the equation:

$$
N=2^{n}+2 n+n_{c}
$$

where $N=$ total number of experimental runs, $n=$ number of independent variables (factors), and $n_{c}=$ number of center points.

Three variables were considered in this study, they are (i) pretreatment temperature " $A$ ", a rice husk activated carbon production variable, (ii) initial phenol concentration " $B$ ", a batch adsorption process variable, and (iii) adsorbent dosage " $C$ ", a batch adsorption process variable.

For three variables, the number of center run was six, therefore number of experimental run required was computed as:

$$
N=2^{n}+2 n+n_{c}=2^{3}+2(3)+6=8+6+6=20 .
$$


TABLE 1: Design matrix for the factors and respective response from experiment.

\begin{tabular}{|c|c|c|c|c|c|c|c|c|c|}
\hline \multirow{2}{*}{ Run } & \multirow{2}{*}{ Type } & \multicolumn{3}{|c|}{ Coded factors } & \multicolumn{3}{|c|}{ Uncoded factors } & \multicolumn{2}{|c|}{ Responses } \\
\hline & & $A\left({ }^{\circ} \mathrm{C}\right)$ & $B(\mathrm{mg} / \mathrm{L})$ & $C(\mathrm{~g})$ & $A\left({ }^{\circ} \mathrm{C}\right)$ & $B(\mathrm{mg} / \mathrm{L})$ & $C(\mathrm{~g})$ & $Y_{1}(\%)$ & $Y_{2}(\mathrm{mg} / \mathrm{g})$ \\
\hline 1 & Factorial & -1 & 1 & -1 & 300 & 50 & 2 & 88.32 & 2.21 \\
\hline 2 & Factorial & 1 & 1 & 1 & 500 & 50 & 4 & 94.70 & 1.18 \\
\hline 3 & Factorial & 1 & 1 & -1 & 500 & 50 & 2 & 95.72 & 2.39 \\
\hline 4 & Axial & 1 & 0 & 0 & 500 & 30 & 3 & 93.86 & 0.94 \\
\hline 5 & Center & 0 & 0 & 0 & 400 & 30 & 3 & 90.47 & 0.91 \\
\hline 6 & Axial & -1 & 0 & 0 & 300 & 30 & 3 & 82.57 & 0.83 \\
\hline 7 & Center & 0 & 0 & 0 & 400 & 30 & 3 & 90.47 & 0.91 \\
\hline 8 & Factorial & -1 & 1 & 1 & 300 & 50 & 4 & 94.17 & 1.18 \\
\hline 9 & Axial & 0 & 1 & 0 & 400 & 50 & 3 & 93.47 & 1.56 \\
\hline 10 & Center & 0 & 0 & 0 & 400 & 30 & 3 & 90.47 & 0.91 \\
\hline 11 & Axial & 0 & -1 & 0 & 400 & 10 & 3 & 75.79 & 0.25 \\
\hline 12 & Axial & 0 & 0 & 1 & 400 & 30 & 4 & 93.68 & 0.70 \\
\hline 13 & Factorial & -1 & -1 & -1 & 300 & 10 & 2 & 56.49 & 0.28 \\
\hline 14 & Factorial & 1 & -1 & -1 & 500 & 10 & 2 & 78.25 & 0.39 \\
\hline 15 & Center & 0 & 0 & 0 & 400 & 30 & 3 & 90.47 & 0.91 \\
\hline 16 & Factorial & -1 & -1 & 1 & 300 & 10 & 4 & 71.93 & 0.18 \\
\hline 17 & Center & 0 & 0 & 0 & 400 & 30 & 3 & 90.47 & 0.91 \\
\hline 18 & Center & 0 & 0 & 0 & 400 & 30 & 3 & 90.47 & 0.91 \\
\hline 19 & Axial & 0 & 0 & -1 & 400 & 30 & 2 & 88.42 & 1.33 \\
\hline 20 & Factorial & 1 & -1 & 1 & 500 & 10 & 4 & 85.79 & 0.21 \\
\hline
\end{tabular}

This implied that 20 experimental runs consisting of 8 factorial runs, 6 axial runs and 6 center runs were required. The two response variables considered in the study were: (i) removal efficiency $\left(Y_{1}\right)$ and (ii) adsorption capacity $\left(Y_{2}\right)$.

2.4.2. Regression Model. Each response was used to develop an empirical model that correlate the response to the three factors that is, rice husk activated carbon preparation variable $(A)$ and batch adsorption process variables $(B, C)$, using second-order polynomial equation [39-41]:

$$
Y=b_{o}+\sum_{i=1}^{n} b_{i} X_{i}+\sum_{i=1}^{n} b_{i i} X_{i}^{2}+\sum_{i=1}^{n-1} \sum_{j=i+1}^{n} b_{i j} X_{i} X_{j},
$$

where $Y$ is the predicted response, $b_{o}$ is the constant coefficient, $b_{i}$ is the linear coefficient, $b_{i j}$ is the interaction coefficient, $b_{i i}$ is the quadratic coefficient, and $X_{i}, X_{j}$ are the coded values for the factors.

2.4.3. Statistical and Graphical Analysis. Significance of the model equations and their terms were evaluated using statistical tools such as coefficient of determination ( $R$-squared), Fisher value ( $F$-value), probability ( $P$ value), and residual [42-44]. Graphs were employed to analyze the combined effect of factors on responses using $3 \mathrm{D}$ plots and to also analyze the predicted versus actual value plots of the response variables.

2.4.4. Optimization. Optimization technique was employed to determine the optimum operating conditions for the process variables under consideration. To achieve this, goals were set with constraints. For each of the factors, goal was set "in range" with constraints 300-500, 10-50, and 2-4 of lower-upper level for factors $A, B$, and $C$, respectively. For the response surface, the goal for $Y_{2}$ was also set "in range" with constraint 0.18-2.393 as lower-upper levels, while the goal for $Y_{1}$ was set "maximize" at 100 . Therefore removal efficiency becomes the objective function or performance index.

2.4.5. Model Validation. Model validation was carried out by conducting batch experiment under optimum operating conditions. In order to evaluate the validity of the model, experimental values obtained were compared with the model predicted values.

2.4.6. Software Application. Design Expert Software (version 8) was used for the design of the experiment, regression, statistical analysis, optimization, and graphical analysis.

\section{Results and Discussion}

3.1. Responses Obtained from the Experiment. Table 1 shows the design matrix consisting of types of run, coded and actual factors as randomized by the software, and respective response obtained from the experiment. From the results, it could be observed that the highest removal efficiency $\left(Y_{1}\right)$ of 95.72\% was obtained and this was followed by the removal efficiency of $94.17 \%$. In terms of adsorption capacity $\left(Y_{2}\right)$, the highest value of $2.39 \mathrm{mg} / \mathrm{g}$ was obtained and this was followed by adsorption capacity of $2.21 \mathrm{mg} / \mathrm{g}$. In comparison, recent studies by Kalderis et al., [13], Kermani et al., [45], Mahvi et 
TABLE 2: Regression statistics for removal efficiency (model for response $Y_{1}$ ).

\begin{tabular}{lccccc}
\hline Source & $\begin{array}{r}\text { Standard } \\
\text { deviation }\end{array}$ & $R^{2}$ & $\begin{array}{c}\text { Adjusted } \\
R^{2}\end{array}$ & $\begin{array}{c}\text { Predicted } \\
R^{2}\end{array}$ & Comment \\
\hline Linear & 5.02 & 0.7729 & 0.7303 & 0.5487 & \\
2FI & 4.29 & 0.8653 & 0.8031 & 0.1189 & \\
Quadratic & $\mathbf{0 . 6 1}$ & $\mathbf{0 . 9 9 7 9}$ & $\mathbf{0 . 9 9 6 0}$ & $\mathbf{0 . 9 8 2 6}$ & Suggested \\
Cubic & 0.056 & 1.0000 & 1.0000 & 0.9871 & Aliased \\
\hline
\end{tabular}

TABLE 3: Regression statistics for adsorption capacity (model for response $Y_{2}$ ).

\begin{tabular}{lccccc}
\hline Source & $\begin{array}{c}\text { Standard } \\
\text { Deviation }\end{array}$ & $R^{2}$ & $\begin{array}{c}\text { Adjusted } \\
R^{2}\end{array}$ & $\begin{array}{c}\text { Predicted } \\
R^{2}\end{array}$ & Comment \\
\hline Linear & 0.19 & 0.9173 & 0.9018 & 0.8114 & \\
2FI & 0.073 & 0.9897 & 0.9850 & 0.9442 & \\
Quadratic & $\mathbf{0 . 0 3 6}$ & $\mathbf{0 . 9 9 8 1}$ & $\mathbf{0 . 9 9 6 3}$ & $\mathbf{0 . 9 8 1 9}$ & Suggested \\
Cubic & $3.00 E-03$ & 1.0000 & 1.0000 & 0.9902 & Aliased \\
\hline
\end{tabular}

al., [46], and Daffalla et al., [47] on adsorption of phenol onto rice husk activated carbon shows that adsorption capacities of $27.58 \mathrm{mg} / \mathrm{g}, 0.886 \mathrm{mg} / \mathrm{g}, 0.95-1 \mathrm{mg} / \mathrm{g}$, and $0.98-46.19 \mathrm{mg} / \mathrm{g}$ were obtained, respectively. The differences in adsorption capacities could be as a result of the influence of the processes employed in the production of the activated carbon which was reported to have significant influence on its performance in adsorption process [48].

3.2. Development of Model Equations. Correlation between the response surface and factors were developed using CCD of the Design Expert software. According to sequential model sum of squares, the models were selected based on the highest order polynomials where the additional terms were significant and the models were not aliased $[49,50]$. Correlation coefficient and standard deviation were used to evaluate the fitness of the models developed. The closer the $R^{2}$ value is to unity and the smaller the standard deviation, the better the model in predicting the response [51].

Table 2 shows that the quadratic model has relatively small standard deviation of 0.61 and relatively high $R^{2}$ value of 0.9979 with predicted $R^{2}(0.9960)$ in reasonable agreement with adjusted $R^{2}(0.9826)$. It was also observed on the table that the quadratic model for response $Y_{1}$ was not aliased. This implies that the quadratic model can be employed to describe the relationship between response $Y_{1}$ and the interacting variables. Table 3 also shows that the quadratic model has relatively small standard deviation of 0.036 and relatively high $R^{2}$ value of 0.9981 with predicted $R^{2}(0.9819)$ in reasonable agreement with adjusted $R^{2}(0.9963)$. It was also observed on the same table that the quadratic model for response $Y_{2}$ was not aliased. This implies that the quadratic model can be employed to describe the relationship between response $Y_{2}$ and the interacting variables.

The $R^{2}$ values of 0.9979 and 0.9981 implied that $99.79 \%$ and $99.81 \%$ of the variation in removal efficiency and adsorption capacity respectively can be attributed to the three factors ( $A$-pretreatment temperature; $B$-initial phenol concentration; $C$-adsorbent dosage) considered. Therefore, the quadratic models were selected as suggested by the software and the response surface model equations in their actual values are

$$
\begin{aligned}
Y_{1}= & -0.000217641 A^{2}-0.014404 B^{2}+0.65959 C^{2} \\
& -0.00173025 A B-0.018465 A C-0.1137 B C \\
& +0.33625 A+2.38714 B+10.1384 C-51.11583 \\
Y_{2}= & -0.00000184545 A^{2}+0.0000113636 B^{2} \\
& +0.11355 C^{2}+0.0000030625 A B \\
& -0.00031625 A C-0.012256 B C+0.00278124 A \\
& +0.070862 B-0.50129 C-0.12217
\end{aligned}
$$

3.3. Statistical Analysis. The model equations selected were further evaluated using ANOVA component of the software. Table 4 shows that response surface quadratic model for removal efficiency has $F$-value of 529.68 indicating that the model is significant. For the model terms, $P$ value less than 0.05 implies that model term is significant [52-55] and largest $\mathrm{F}$-value signifies the model term having the most significant effect on the response $[50,56]$. In this case, the significant model terms are $A, B, C, A B, A C, B C, A^{2}$, and $B^{2}$ while $C^{2}$ is the insignificant model term. The model term having the most significant effect on the response is $B$ with $F$-value of 2589.51 and the effect is in the order $B>A>C>$ $A B>B^{2}>B C>A C>A^{2}$. Table 5 shows that response surface quadratic model for adsorption capacity has $F$-value of 570.02 indicating that the model is significant. In this case, the significant model terms are $A, B, C, A C, B C$, and $C^{2}$ while $A B, A^{2}$, and $B^{2}$ are insignificant model terms. The model term having the most significant effect on the response is $B$ with $F$ value of 3947.85 and the effect is in the order $B>C>B C>$ $C^{2}>A>A C$.

Therefore, removing the insignificant model terms, the quadratic models for the responses become:

$$
\begin{aligned}
Y_{1}= & -0.000217641 A^{2}-0.014404 B^{2}-0.00173025 A B \\
& -0.018465 A C-0.1137 B C+0.33625 A \\
& +2.38714 B+10.1384 C-51.11583 \\
Y_{2}= & 0.11355 C^{2}-0.00031625 A C-0.012256 B C \\
& +0.00278124 A+0.070862 B-0.50129 C \\
& -0.12217
\end{aligned}
$$

The residual of the response surface models presented in Tables 5 and 6 shows that the highest-lowest error (residual) for response $Y_{1}$ is $1.02-0.03 \%$ and that of $Y_{2}$ is $0.07-$ $0.00027 \mathrm{mg} / \mathrm{g}$. This also signifies the quality of the models in terms of predicting the responses. 
TABLE 4: ANOVA table for removal efficiency (model for response $Y_{1}$ ).

\begin{tabular}{|c|c|c|c|c|c|c|}
\hline Source & Sum of squares & df & Mean square & $F$-value & $P$ value & Comment \\
\hline Model & 1773.14 & 9 & 197.02 & 529.63 & $<0.0001$ & Significant \\
\hline$A$ & 300.64 & 1 & 300.64 & 808.29 & $<0.0001$ & Significant \\
\hline$B$ & 963.17 & 1 & 963.17 & 2589.51 & $<0.0001$ & Significant \\
\hline C & 109.47 & 1 & 109.47 & 294.33 & $<0.0001$ & Significant \\
\hline$A B$ & 95.8 & 1 & 95.8 & 257.56 & $<0.0001$ & Significant \\
\hline$A C$ & 27.28 & 1 & 27.28 & 73.33 & $<0.0001$ & Significant \\
\hline$B C$ & 41.13 & 1 & 41.13 & 110.59 & $<0.0001$ & Significant \\
\hline$A^{2}$ & 13.07 & 1 & 13.07 & 35.02 & 0.0001 & Significant \\
\hline$B^{2}$ & 91.28 & 1 & 91.28 & 245.42 & $<0.0001$ & Significant \\
\hline$C^{2}$ & 1.2 & 1 & 1.2 & 3.22 & 0.1031 & \\
\hline Residual & 3.72 & 10 & 0.37 & & & \\
\hline
\end{tabular}

TABLE 5: ANOVA table for adsorption capacity (model for response $Y_{2}$ ).

\begin{tabular}{lcccccc}
\hline Source & Sum of squares $\times 10^{-2}$ & $\mathrm{df}$ & Mean square $\times 10^{-2}$ & $F$-value & $P$ value & Comment \\
\hline Model & 674 & 9 & 75 & 570.02 & $<0.0001$ & Significant \\
$A$ & 2 & 1 & 2 & 15.28 & 0.0029 & Significant \\
$B$ & 518 & 1 & 518 & 3947.56 & $<0.0001$ & Significant \\
$C$ & 99 & 1 & 99 & 751.81 & $<0.0001$ & Significant \\
$A B$ & 0.03 & 1 & 0.03 & 6.09 & 0.0429 & Significant \\
$A C$ & 0.8 & 1 & 0.8 & 366.07 & $<0.0001$ & Significant \\
$B C$ & 48 & 1 & 48 & 0.71 & 0.4181 \\
$A^{2}$ & 0.094 & 1 & 0.094 & 0.043 & 0.8394 \\
$B^{2}$ & 0.0057 & 1 & 0.0057 & 27 & 0.0004 & Significant \\
$C^{2}$ & 3.5 & 10 & 0.13 & & \\
Residual & 1.3 & & 3.5 & & \\
\hline
\end{tabular}

TABLE 6: Actual-predicted values and residual.

\begin{tabular}{|c|c|c|c|c|c|c|}
\hline \multirow{2}{*}{ Run } & \multicolumn{3}{|c|}{ Response $Y_{1}(\%)$} & \multicolumn{3}{|c|}{ Response $Y_{2}(\mathrm{mg} / \mathrm{g})$} \\
\hline & Actual & Predicted & Residual & Actual & Predicted & Residual \\
\hline 1 & 88.32 & 88.06 & 0.25 & 2.21 & 2.20 & 0.0082 \\
\hline 2 & 94.70 & 94.19 & 0.51 & 1.18 & 1.18 & 0.001 \\
\hline 3 & 95.72 & 95.8 & 0.083 & 2.39 & 2.36 & 0.028 \\
\hline 4 & 93.86 & 93.74 & 0.12 & 0.94 & 0.93 & 0.0093 \\
\hline 5 & 90.47 & 90.44 & 0.03 & 0.91 & 0.90 & 0.0016 \\
\hline 6 & 82.57 & 82.78 & 0.21 & 0.83 & 0.84 & 0.014 \\
\hline 7 & 90.47 & 90.44 & 0.03 & 0.91 & 0.90 & 0.0016 \\
\hline 8 & 94.17 & 93.84 & 0.34 & 1.18 & 1.14 & 0.033 \\
\hline 9 & 93.47 & 94.49 & 1.02 & 1.56 & 1.63 & 0.07 \\
\hline 10 & 90.47 & 90.44 & 0.03 & 0.91 & 0.90 & 0.0016 \\
\hline 11 & 75.79 & 74.86 & 0.93 & 0.25 & 0.19 & 0.065 \\
\hline 12 & 93.68 & 94.41 & 0.72 & 0.70 & 0.70 & 0.00027 \\
\hline 13 & 56.49 & 56.98 & 0.49 & 0.28 & 0.28 & 0.00021 \\
\hline 14 & 78.25 & 78.56 & 0.31 & 0.39 & 0.42 & 0.31 \\
\hline 15 & 90.47 & 90.44 & 0.03 & 0.91 & 0.90 & 0.0016 \\
\hline 16 & 71.93 & 71.82 & 0.11 & 0.18 & 0.21 & 0.027 \\
\hline 17 & 90.47 & 90.44 & 0.03 & 0.91 & 0.90 & 0.0016 \\
\hline 18 & 90.47 & 90.44 & 0.03 & 0.91 & 0.90 & 0.0016 \\
\hline 19 & 88.42 & 87.79 & 0.63 & 1.33 & 1.33 & 0.0051 \\
\hline 20 & 85.79 & 86.02 & 0.23 & 0.21 & 0.22 & 0.0069 \\
\hline
\end{tabular}




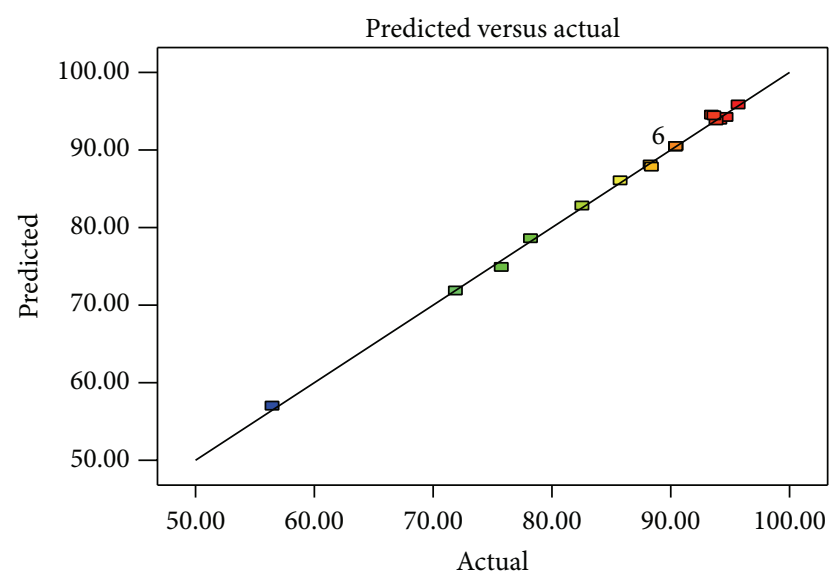

Design-expert software efficiency Color points by value of efficiency:

95.719

56.491

FIgURE 1: Actual-predicted plot for response $Y_{1}$.

The plots of actual versus predicted values of response $Y_{1}$ and $Y_{2}$ in Figures 1 and 2, respectively, show very minimal divergence of points from the diagonal indicating that these response surface model equations can be used to adequately represent the interaction of the three factors.

\subsection{Combined Effect of Factors on Response}

3.4.1. Combined Effect of Temperature and Initial Concentration at Constant Adsorbent Dosage. Figure 3 shows the combined effect of temperature and initial concentration on removal efficiency. It was observed that the two factors have significant combined effect on removal efficiency and increase in any of the factors reasonably increases the removal efficiency. The combined effect was observed to be greater at higher values of the two factors. The combined effect of temperature and initial concentration on adsorption capacity is as shown in Figure 4. The figure shows that the combined effect is almost completely as a result of the singular effect of initial concentration with temperature having very small effect. It was also observed that adsorption capacity is significantly increased with increase in initial concentration whereas increase in temperature results in relatively very small increase in adsorption capacity.

\subsubsection{Combined Effect of Temperature and Adsorbent Dosage} at Constant Initial Concentration. Figure 5 shows that temperature and adsorbent dosage have relatively small combined effect on removal efficiency. It was observed that the effect of temperature is relatively higher than that of adsorbent dosage and increase in any of the two factors increases the removal efficiency. Figure 6 shows the combined effect of temperature and adsorbent dosage on adsorption capacity. It was observed that adsorbent dosage greatly controls the combined effect of the two factors with temperature having

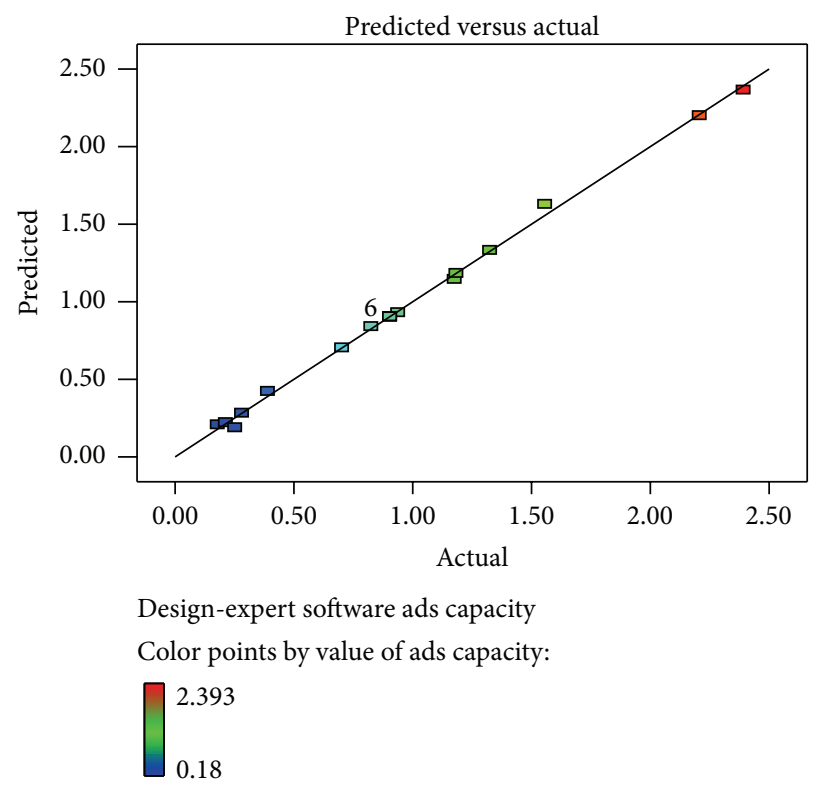

Figure 2: Actual-predicted plot for response $Y_{2}$.

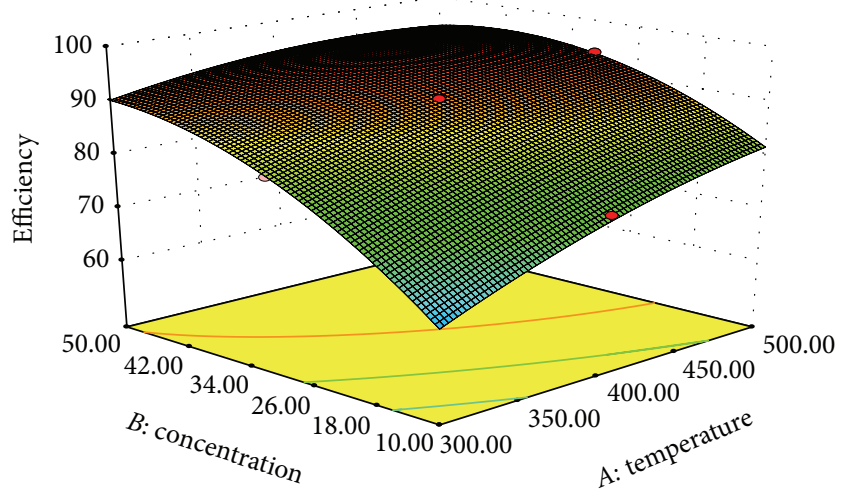

Design-expert software

Factor coding: actual

Efficiency

- Design points above predicted value

- Design points below predicted value

95.719

56.491

$X 1=A$ : temperature

$X 2=B$ : concentration

Actual factor

C: dosage $=3.00$

Figure 3: Combined effect of factors $A-B$ on response $Y_{1}$.

very little effect. It was also observed that increasing the adsorbent dosage decreases the adsorption capacity.

3.4.3. Combined Effect of Initial Concentration and Adsorbent Dosage at Constant Temperature. Figure 7 shows that initial concentration and adsorbent dosage have significant combined effect on removal efficiency with initial concentration 


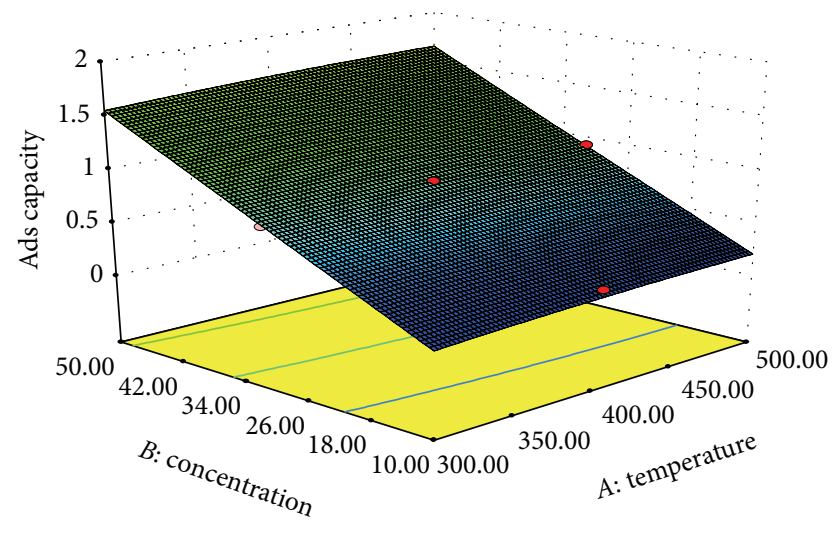

Design-expert software

Factor coding: actual

Ads capacity

- Design points above predicted value

- Design points below predicted value

2.393

0.18

$X 1=A$ : temperature

$X 2=B$ : concentration

Actual factor

$C:$ dosage $=3.00$

Figure 4: Combined effect of factors $A-B$ on response $Y_{2}$.

exhibiting the greatest effect though adsorbent dosage shows reasonable effect too. The combined effect was observed to be greater at higher values of the two factors. It was also observed that increasing any of the factors increases the removal efficiency. Figure 8 shows that the two factors have significant combined effect on adsorption capacity. It was observed that, at higher initial concentration, increase in adsorbent dosage greatly decreases the adsorption capacity than at lower initial concentrations. Increase in initial concentration was also observed to increase the adsorption capacity but with much effect at lower adsorbent dosage.

3.5. Optimization. Optimization of the two responses under the same condition is difficult because the interest regions of factors are different. When $Y_{1}$ increases, $Y_{2}$ decreases and vice versa. Therefore the function of desirability was applied and the operating condition with the highest desirability was considered as selected by the software. Hence, the optimum operating conditions for the production of rice husk activated carbon and batch adsorption of phenol using the rice husk activated carbon are as follows.

Factors
A-temperature of pretreatment $=441.46^{\circ} \mathrm{C}$,
$B$-initial phenol concentration $=40.61 \mathrm{mg} / \mathrm{L}$,
$C$-activated carbon dosage $=4 \mathrm{~g}$.

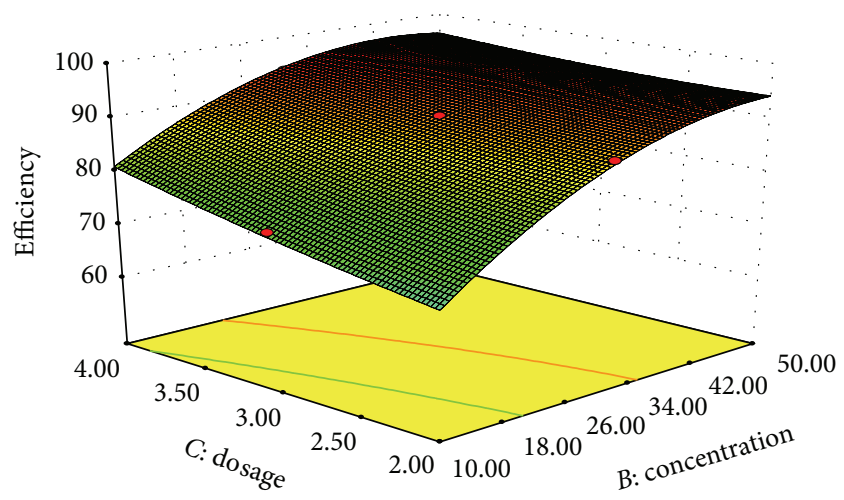

Design-expert software

Factor coding: actual

Efficiency

- Design points above predicted value

○ Design points below predicted value

95.719

56.491

$X 1=B$ : concentration

$X 2=C$ : dosage

Actual factor

A: temperature $=400.00$

Figure 5: Combined effect of factors $A-C$ on response $Y_{1}$.

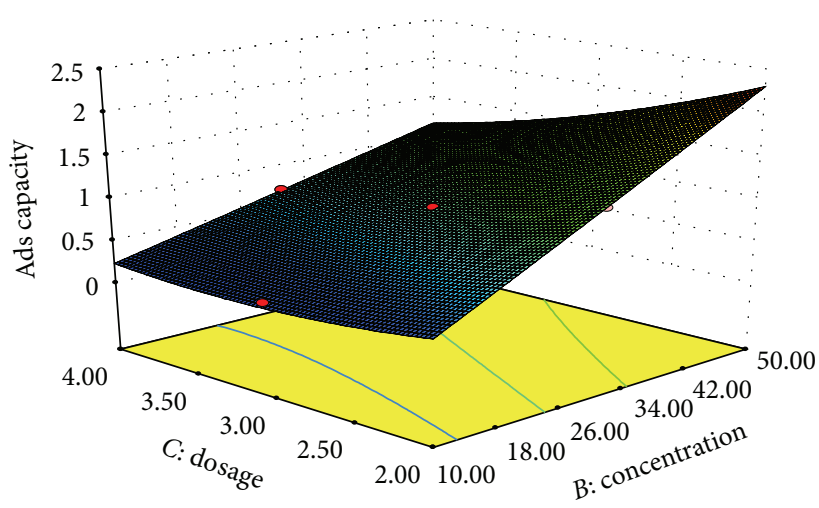

Design-expert software

Factor coding: actual

Ads capacity

- Design points above predicted value

- Design points below predicted value

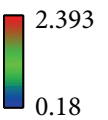

$X 1=B:$ concentration

$X 2=C$ : dosage

Actual factor

A: temperature $=400.00$

Figure 6: Combined effect of factors $A-C$ on response $Y_{2}$. 
TABLE 7: Model validation.

\begin{tabular}{ccccccccc}
\hline \multirow{2}{*}{$\mathrm{Tp}\left({ }^{\circ} \mathrm{C}\right)$} & \multirow{2}{*}{$\mathrm{m}(\mathrm{g})$} & \multirow{2}{*}{$C_{o}(\mathrm{mg} / \mathrm{L})$} & \multicolumn{2}{c}{ Experimental } & \multicolumn{2}{c}{ Theoretical } & \multicolumn{3}{c}{ Percentage error } \\
& & & $q_{e}(\mathrm{mg} / \mathrm{g})$ & $\mathrm{RE}(\%)$ & $q_{e}(\mathrm{mg} / \mathrm{g})$ & $\mathrm{RE}(\%)$ & $q_{e}$ & $\mathrm{RE}$ \\
\hline 441.46 & 4 & 40.61 & 0.969 & 95.464 & 0.960 & 97.160 & 1.000 & 1.777 \\
\hline
\end{tabular}

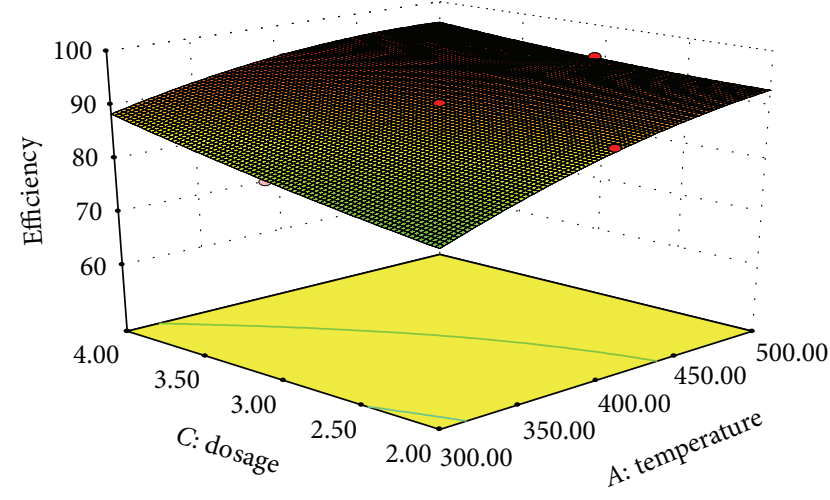

Design-expert software

Factor coding: actual

Efficiency

- Design points above predicted value

○ Design points below predicted value

$\prod_{56.491}^{95.719}$
$X 1=A$ : temperature
$X 2=C$ : dosage
Actual factor
$B$ : concentration $=30.00$

Figure 7: Combined effect of factors $B-C$ on response $Y_{1}$.

Response

$$
\begin{aligned}
& Y_{1} \text {-removal efficiency }=97.1608 \%, \\
& Y_{2} \text {-adsorption capacity }=0.9595 \mathrm{mg} / \mathrm{g} .
\end{aligned}
$$

3.6. Model Validation. Table 7 compares the results of experimental values with predicted values under optimum operating condition. It can be seen from the table that the percentage error of experimental against predicted value for adsorption capacity and removal efficiency are $1 \%$ and $1.777 \%$, respectively. Therefore, this shows that the models and optimum operating condition developed for the factors are valid and applicable in predicting the response variables.

\section{Conclusions}

The quadratic models developed have $R^{2}$ values of 0.9979 and 0.9981 for removal efficiency and adsorption capacity, respectively. Therefore, $99.79 \%$ and $99.81 \%$ of the variations in removal efficiency and adsorption capacity, respectively, are attributed to the three process variables considered and the models can be used to predict the interaction of the process variables. Modeling revealed that, aside singular
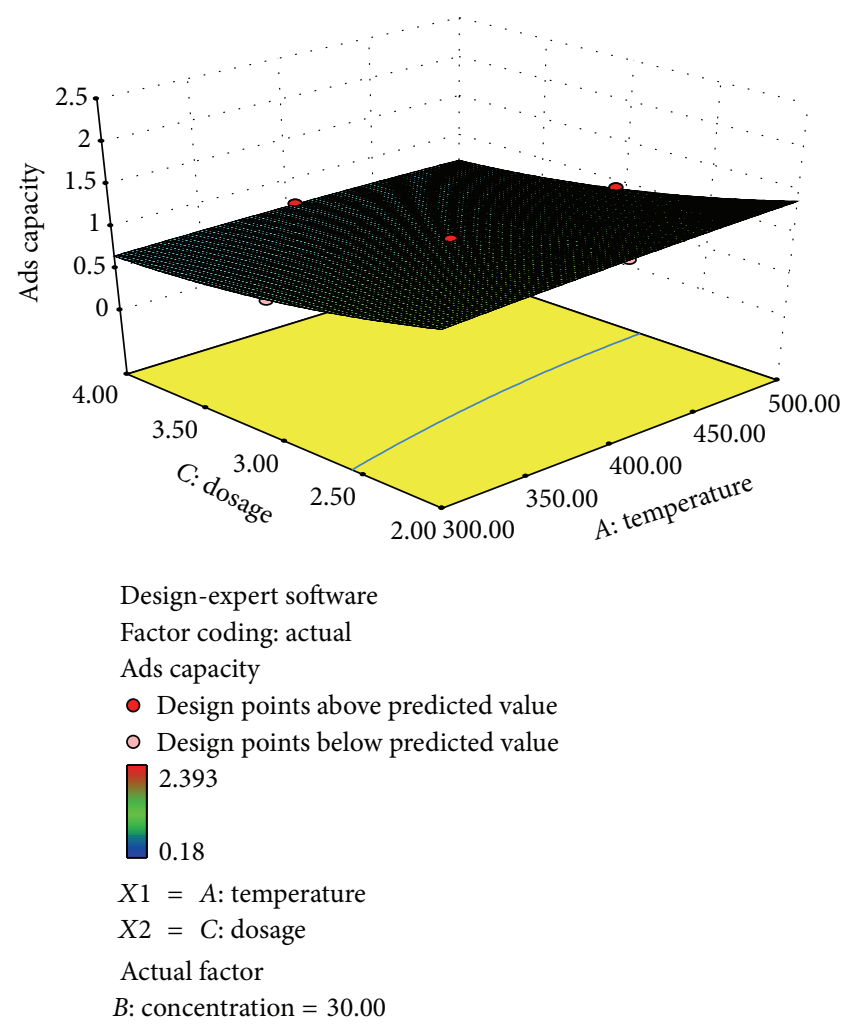

Figure 8: Combined effect of factors $B-C$ on response $Y_{2}$.

effect, interaction of factors also significantly affects the adsorption capacity and removal efficiency. The single effect of the three process variables on adsorption capacity is in the order: initial solute concentration > adsorbent dosage > pretreatment temperature, while that of removal efficiency is in the order: initial solute concentration > pretreatment temperature $>$ adsorbent dosage. Optimization revealed that the optimum operating condition for the adsorption process is initial solute concentration $40.61 \mathrm{mg} / \mathrm{L}$; pretreatment temperature $441.46^{\circ} \mathrm{C}$; adsorbent dosage $4 \mathrm{~g}$; adsorption capacity $0.9595 \mathrm{mg} / \mathrm{g}$; removal efficiency $97.16 \%$.

\section{Conflict of Interests}

The authors declare that there is no conflict of interests regarding the publication of this paper.

\section{References}

[1] J. N. Sahu, J. Acharya, and B. C. Meikap, "Response surface modeling and optimization of chromium(VI) removal from aqueous solution using Tamarind wood activated carbon in 
batch process," Journal of Hazardous Materials, vol. 172, no. 2-3, pp. 818-825, 2009.

[2] F. Benyahia, M. Abdulkarim, A. Embaby, and M. Rao, "Refinery wastewater treatment: a true technological challenge," in Proceedings of the 7th Annual U.A.E. University Research Conference, 2004.

[3] S. P. Kamble, P. A. Mangrulkar, A. K. Bansiwal, and S. S. Rayalu, "Adsorption of phenol and $o$-chlorophenol on surface altered fly ash based molecular sieves," Chemical Engineering Journal, vol. 138, no. 1-3, pp. 73-83, 2008.

[4] A. Bhatnagar and A. K. Minocha, "Conventional and nonconventional adsorbents for removal of pollutants from watera review," Indian Journal of Chemical Technology, vol. 13, no. 3, pp. 203-217, 2006.

[5] R. Qadeer and S. Akhtar, "Kinetics study of lead ion adsorption on active carbon," Turkish Journal of Chemistry, vol. 29, no. 1, pp. 95-99, 2005.

[6] M. H. El-Naas, S. Al-Zuhair, and M. A. Alhaija, "Removal of phenol from petroleum refinery wastewater through adsorption on date-pit activated carbon," Chemical Engineering Journal, vol. 162, no. 3, pp. 997-1005, 2010.

[7] Q.-S. Liu, T. Zheng, P. Wang, J.-P. Jiang, and N. Li, “Adsorption isotherm, kinetic and mechanism studies of some substituted phenols on activated carbon fibers," Chemical Engineering Journal, vol. 157, no. 2-3, pp. 348-356, 2010.

[8] R. Han, D. Ding, Y. Xu et al., "Use of rice husk for the adsorption of congo red from aqueous solution in column mode," Bioresource Technology, vol. 99, no. 8, pp. 2938-2946, 2008.

[9] F. Kadhim and F. A. Al-Seroury, "Characterization the removal of phenol from aqueous solution in fluidized bed column by rice husk adsorbent," Research Journal of Recent Sciences, vol. 1, no. ISC-2011, pp. 145-151, 2012.

[10] X. Song, Y. Zhang, C. Yan, W. Jiang, and C. Chang, "The Langmuir monolayer adsorption model of organic matter into effective pores in activated carbon," Journal of Colloid and Interface Science, vol. 389, no. 1, pp. 213-219, 2013.

[11] G. Aidan, "Agricultural wastes and activated carbon from them for furfural removal from water solutions," Life Science Journal, vol. 9, p. 3, 2012.

[12] V. Fierro, V. Torné-Fernández, D. Montané, and A. Celzard, "Adsorption of phenol onto activated carbons having different textural and surface properties," Microporous and Mesoporous Materials, vol. 111, no. 1-3, pp. 276-284, 2008.

[13] D. Kalderis, S. Bethanis, P. Paraskeva, and E. Diamadopoulos, "Production of activated carbon from bagasse and rice husk by a single-stage chemical activation method at low retention times," Bioresource Technology, vol. 99, no. 15, pp. 6809-6816, 2008.

[14] K. P. Singh, S. Gupta, A. K. Singh, and S. Sinha, "Experimental design and response surface modeling for optimization of Rhodamine B removal from water by magnetic nanocomposite," Chemical Engineering Journal, vol. 165, no. 1, pp. 151-160, 2010.

[15] D. Xin-hui, C. Srinivasakannan, W.-W. Qu, W. Xin, P. Jinhui, and Z. Li-bo, "Regeneration of microwave assisted spent activated carbon: process optimization, adsorption isotherms and kinetics," Chemical Engineering and Processing: Process Intensification, vol. 53, pp. 53-62, 2012.

[16] K. Anupam, S. Dutta, C. Bhattacharjee, and S. Datta, "Adsorptive removal of chromium (VI) from aqueous solution over powdered activated carbon: optimisation through response surface methodology," Chemical Engineering Journal, vol. 173, no. 1, pp. 135-143, 2011.
[17] A. R. Khataee, "Optimization of UV-promoted peroxydisulphate oxidation of C.I. basic blue 3 using response surface methodology," Environmental Technology, vol. 31, no. 1, pp. 7386, 2010.

[18] A. A. Ahmad, B. H. Hameed, and A. L. Ahmad, "Removal of disperse dye from aqueous solution using waste-derived activated carbon: optimization study," Journal of Hazardous Materials, vol. 170, no. 2-3, pp. 612-619, 2009.

[19] A. R. Khataee, "Application of central composite design for the optimization of photodestruction of a textile dye using UV/S2O82 process," Polish Journal of Chemical Technology, vol. 11, pp. 38-45, 2009.

[20] K. K. Kudaybergenov, E. K. Ongarbayev, and Z. A. Mansurov, "Thermally treated rice husks for petroleum adsorption," International Journal of Biology and Chemistry, vol. 1, pp. 3-12, 2012.

[21] A. O. Alade, O. S. Amuda, A. O. Afolabi, and F. E. Adelowo, "Adsorption of acenaphthene unto activated carbon produced from agricultural wastes," Journal of Environmental Science and Technology, vol. 5, no. 4, pp. 192-202, 2012.

[22] P. E. Dim and J. O. Okafor, "Development and characterization of adsorbent from coconut shells for purification of dye wastewater," Journal of Science, Technology, Mathematics and Education, vol. 8, no. 3, pp. 68-80, 2012.

[23] S. E. Agarry and M. O. Aremu, "Batch equilibrium and kinetic studies of simultaneous adsorption and biodegradation of phenol by pineapple peels immobilized Pseudomonas Aeruginosa NCIB 950," British Biotechnology Journal, vol. 2, no. 1, pp. 2648, 2012.

[24] K. Belgin, T. Fatma, D. Hakan, and D. İlknur, "Liquid phase adsorption of phenol by activated carbon derived from hazelnut bagasse," International journal of Environmental Application \& Science, vol. 3, no. 5, pp. 373-380, 2008.

[25] E. Demirbas, N. Dizge, M. T. Sulak, and M. Kobya, "Adsorption kinetics and equilibrium of copper from aqueous solutions using hazelnut shell activated carbon," Chemical Engineering Journal, vol. 148, no. 2-3, pp. 480-487, 2009.

[26] S. Karaca, A. Gürses, M. Açikyildiz, and M. Ejder (Korucu), "Adsorption of cationic dye from aqueous solutions by activated carbon," Microporous and Mesoporous Materials, vol. 115, no. 3, pp. 376-382, 2008.

[27] U. Garg, M. P. Kaur, G. K. Jawa, D. Sud, and V. K. Garg, "Removal of cadmium (II) from aqueous solutions by adsorption on agricultural waste biomass," Journal of Hazardous Materials, vol. 154, no. 1-3, pp. 1149-1157, 2008.

[28] S.-F. Lo, S.-Y. Wang, M.-J. Tsai, and L.-D. Lin, "Adsorption capacity and removal efficiency of heavy metal ions by Moso and Ma bamboo activated carbons," Chemical Engineering Research and Design, vol. 90, no. 9, pp. 1397-1406, 2012.

[29] S. A. Saad, K. M. Isa, and R. Bahari, "Chemically modified sugarcane bagasse as a potentially low-cost biosorbent for dye removal," Desalination, vol. 264, no. 1-2, pp. 123-128, 2010.

[30] K. J. Cronje, K. Chetty, M. Carsky, J. N. Sahu, and B. C. Meikap, "Optimization of chromium(VI) sorption potential using developed activated carbon from sugarcane bagasse with chemical activation by zinc chloride," Desalination, vol. 275, no. 1-3, pp. 276-284, 2011.

[31] E. M. Y. Nasehir-Khan, L. M. Faizal, A. Ismail, S. B. Olugbenga, and A. A. Mohd, "Process optimization for Zn (II) removal by activated carbon prepared from rice husk using chemical activation," International Journal of Basic \& Applied Sciences, vol. 10, no. 6, p. 132, 2010. 
[32] S. Sugashini and K. M. M. Sheriffa Begum, "Column adsorption studies for the removal of $\mathrm{Cr}(\mathrm{VI})$ ions by ethylamine modified chitosan carbonized rice husk composite beads with modelling and optimization," Journal of Chemistry, vol. 2013, Article ID 460971, 11 pages, 2013.

[33] A. A. Ahmad and B. H. Hameed, "Effect of preparation conditions of activated carbon from bamboo waste for real textile wastewater," Journal of Hazardous Materials, vol. 173, no. 1-3, pp. 487-493, 2010.

[34] R. Hoseinzadeh Hesas, A. Arami-Niya, W. M. A. Wan Daud, and J. N. Sahu, "Preparation of granular activated carbon from oil palm shell by microwave-induced chemical activation: optimisation using surface response methodology," Chemical Engineering Research and Design, vol. 91, no. 12, pp. 2447-2456, 2013.

[35] S. Khodadoust, M. Ghaedi, R. Sahraei, and A. Daneshfar, "Application of experimental design for removal of sunset yellow by copper sulfide nanoparticles loaded on activated carbon," Journal of Industrial and Engineering Chemistry, vol. 20, no. 5, pp. 2663-2670, 2014.

[36] J. N. Sahu, J. Acharya, and B. C. Meikap, "Optimization of production conditions for activated carbons from Tamarind wood by zinc chloride using response surface methodology," Bioresource Technology, vol. 101, no. 6, pp. 1974-1982, 2010.

[37] S. T. Abbas, "Modeling and optimization of adsorption of heavy metal ions onto local activated carbon," Aquatic Science and Technology, vol. 1, no. 2, pp. 108-134, 2013.

[38] M. Arulkumar, P. Sathishkumar, and T. Palvannan, "Optimization of Orange $\mathrm{G}$ dye adsorption by activated carbon of Thespesia populnea pods using response surface methodology," Journal of Hazardous Materials, vol. 186, no. 1, pp. 827-834, 2011.

[39] M. Amini, H. Younesi, and N. Bahramifar, "Statistical modeling and optimization of the cadmium biosorption process in an aqueous solution using Aspergillus niger," Colloids and Surfaces A: Physicochemical and Engineering Aspects, vol. 337, pp. 67-73, 2009.

[40] D. Lalitendu, K. Praveen, A. O. Jason, and J. C. John, "Adsorption of $p$-cresol on granular activated carbon," CIGR Journal, vol. 14, no. 4, 2012.

[41] A. Manase, "Optimization of tea waste activated carbon preparation parameters for removal of cibacron yellow dye from textile wastewaters," International Journal of Advanced Engineering Research and Studies, vol. 1, no. 4, pp. 50-56, 2012.

[42] A. Hassani, L. Alidokht, A. R. Khataee, and S. Karaca, "Optimization of comparative removal of two structurally different basic dyes using coal as a low-cost and available adsorbent," Journal of the Taiwan Institute of Chemical Engineers, vol. 45, no. 4, pp. 1597-1607, 2014.

[43] L. S. de Lima, M. D. M. Araujo, S. P. Quináia, D. W. Migliorine, and J. R. Garcia, "Adsorption modeling of $\mathrm{Cr}$, $\mathrm{Cd}$ and $\mathrm{Cu}$ on activated carbon of different origins by using fractional factorial design," Chemical Engineering Journal, vol. 166, no. 3, pp. 881889, 2011.

[44] P. Roy, N. K. Mondal, and K. Das, "Modeling of the adsorptive removal of arsenic: a statistical approach," Journal of Environmental Chemical Engineering, vol. 2, no. 1, pp. 585-597, 2014.

[45] M. Kermani, H. Pourmoghaddas, B. Bina, and Z. Khazaei, "Removal of phenol from aqueous solutions by rice husk ash and activated carbon," Pakistan Journal of Biological Sciences, vol. 9, no. 10, pp. 1905-1910, 2006.

[46] A. H. Mahvi, A. Maleki, and A. Eslami, "Potential of rice husk and rice husk ash for phenol removal in aqueous systems,"
American Journal Applied Sciences, vol. 1, no. 4, pp. 321-326, 2004.

[47] S. B. Daffalla, M. Hilmi, and S. S. Maizatul, "Batch Studies of Adsorption of Phenol from Aqueous Solutions Using Rice Husk Ash," February 2013, http://eprints.utp.edu.my/8817/1/ 1569558107-new.pdf.

[48] J. Rivera-Utrilla, M. Sánchez-Polo, V. Gómez-Serrano, P. M. Álvarez, M. C. M. Alvim-Ferraz, and J. M. Dias, "Activated carbon modifications to enhance its water treatment applications. An overview," Journal of Hazardous Materials, vol. 187, no. 1-3, pp. 1-23, 2011.

[49] N. Chaudhary and C. Balomajumder, "Optimization study of adsorption parameters for removal of phenol on aluminum impregnated fly ash using response surface methodology," Journal of the Taiwan Institute of Chemical Engineers, vol. 45, no. 3, pp. 852-859, 2014.

[50] I. A. W. Tan, A. L. Ahmad, and B. H. Hameed, "Preparation of activated carbon from coconut husk: optimization study on removal of 2,4,6-trichlorophenol using response surface methodology," Journal of Hazardous Materials, vol. 153, no. 1-2, pp. 709-717, 2008.

[51] M. Z. Alam, E. S. Ameem, S. A. Muyibi, and N. A. Kabbashi, "The factors affecting the performance of activated carbon prepared from oil palm empty fruit bunches for adsorption of phenol," Chemical Engineering Journal, vol. 155, no. 1-2, pp. 191198, 2009.

[52] J. K. Basu, D. Monal, and G. Pinaki, "Statistical optimization for the prediction of ibuprofen adsorption capacity by using microwave assisted activated carbon," Archives of Applied Science Research, vol. 4, no. 2, pp. 1053-1060, 2012.

[53] R. Gottipati and S. Mishra, "Application of response surface methodology for optimization of $\mathrm{Cr}(\mathrm{III})$ and $\mathrm{Cr}(\mathrm{VI})$ adsorption on commercial activated carbons," Research Journal of Chemical Sciences, vol. 2, no. 2, pp. 40-48, 2012.

[54] E. M. Y. Nasehir-Khan, L. M. Faizal, A. Ismail, S. B. Olugbenga, and A. A. Mohd, "Effect of preparation conditions of activated carbon prepared from rice husk by $\mathrm{CO}_{2}$ activation for removal of $\mathrm{Cu}$ (II) from aqueous solution," International Journal of Engineering \& Technology, vol. 10, no. 6, 2010.

[55] S. M. Rusly and S. Ibrahim, "Adsorption of textile reactive dye by palm shell activated carbon: response Surface Methodology," World Academy of Science, Engineering and Technology, vol. 43, pp. 892-895, 2010.

[56] M. H. Kalavathy, I. Regupathi, M. G. Pillai, and L. R. Miranda, "Modelling, analysis and optimization of adsorption parameters for $\mathrm{H}_{3} \mathrm{PO}_{4}$ activated rubber wood sawdust using response surface methodology (RSM)," Colloids and Surfaces B: Biointerfaces, vol. 70, no. 1, pp. 35-45, 2009. 

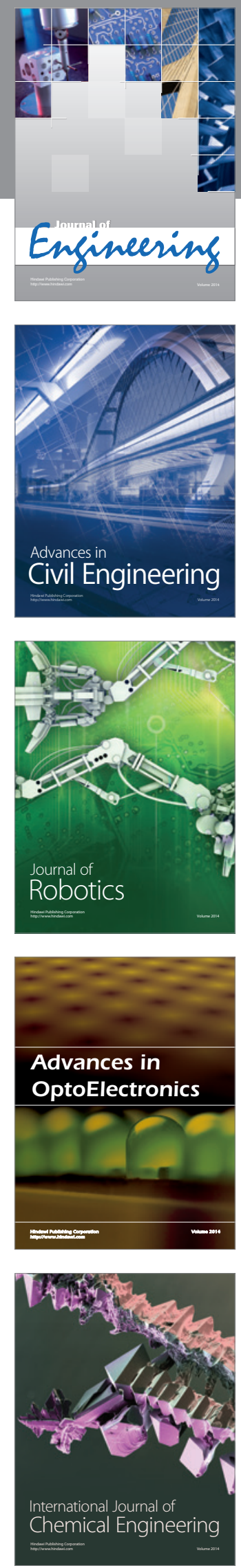

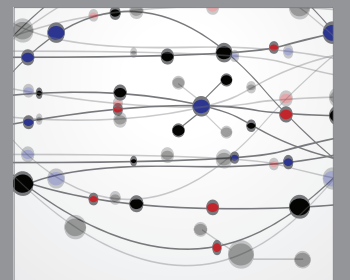

The Scientific World Journal
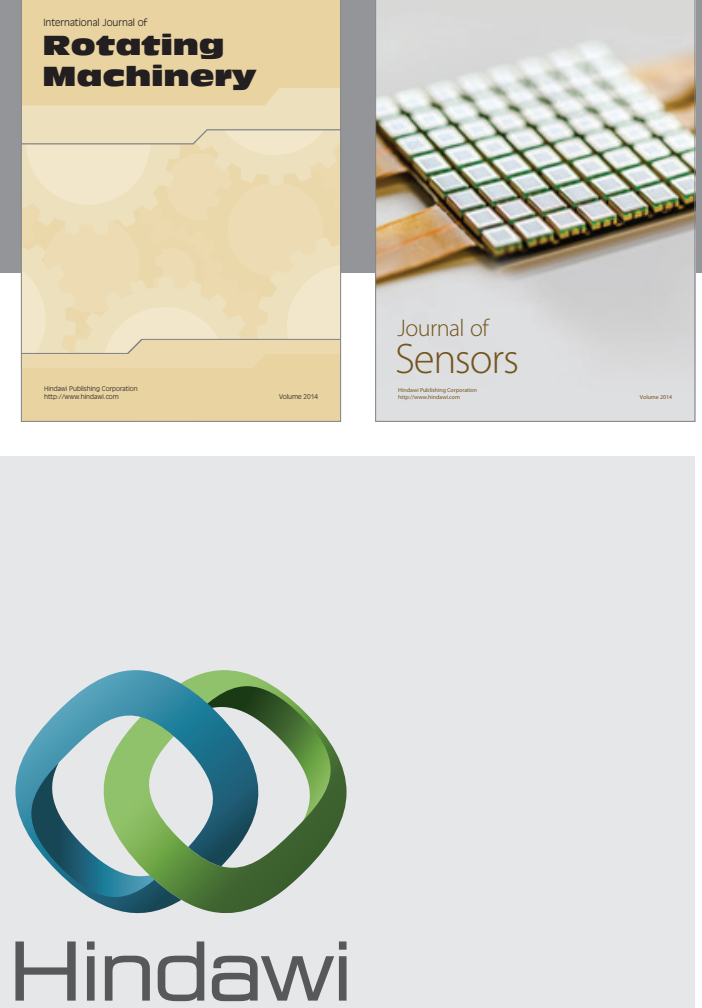

Submit your manuscripts at http://www.hindawi.com
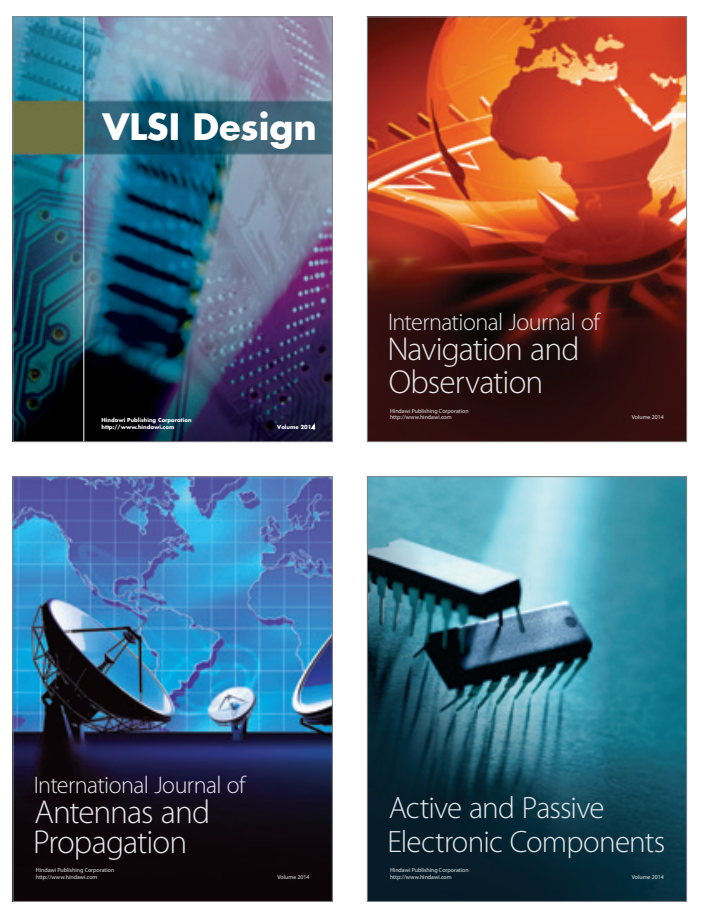
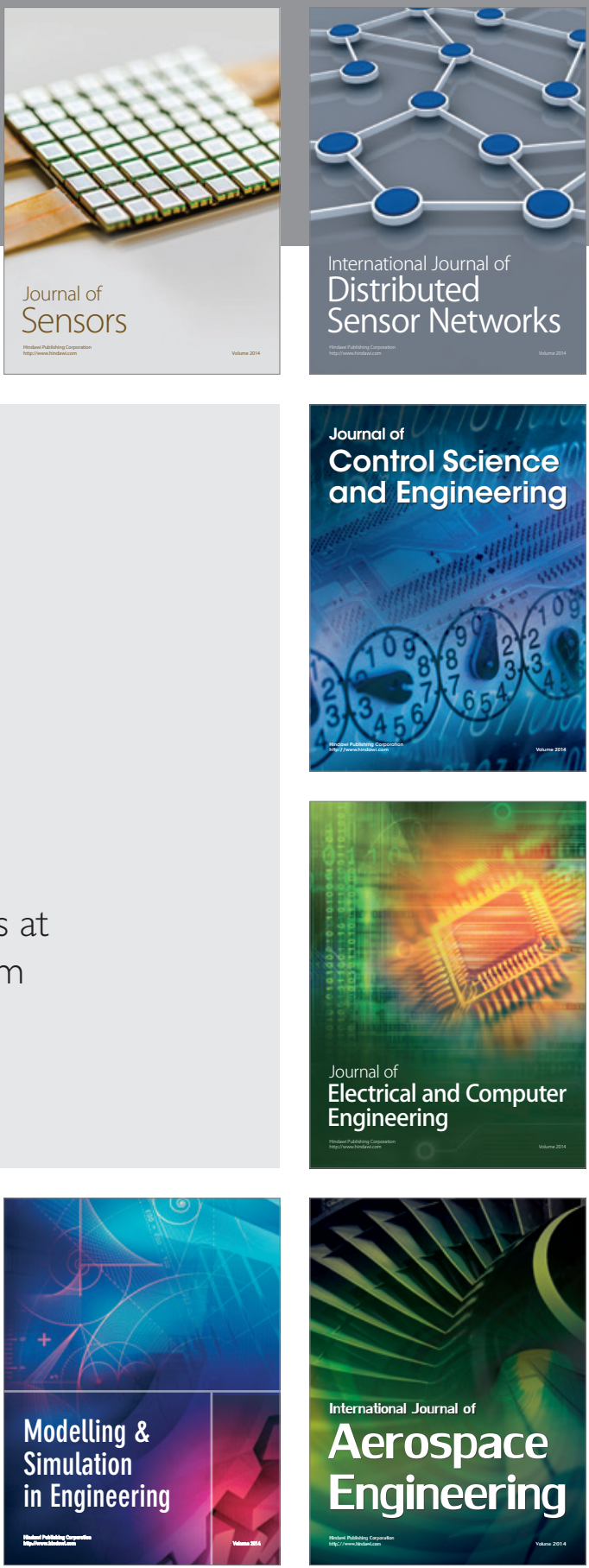

Journal of

Control Science

and Engineering
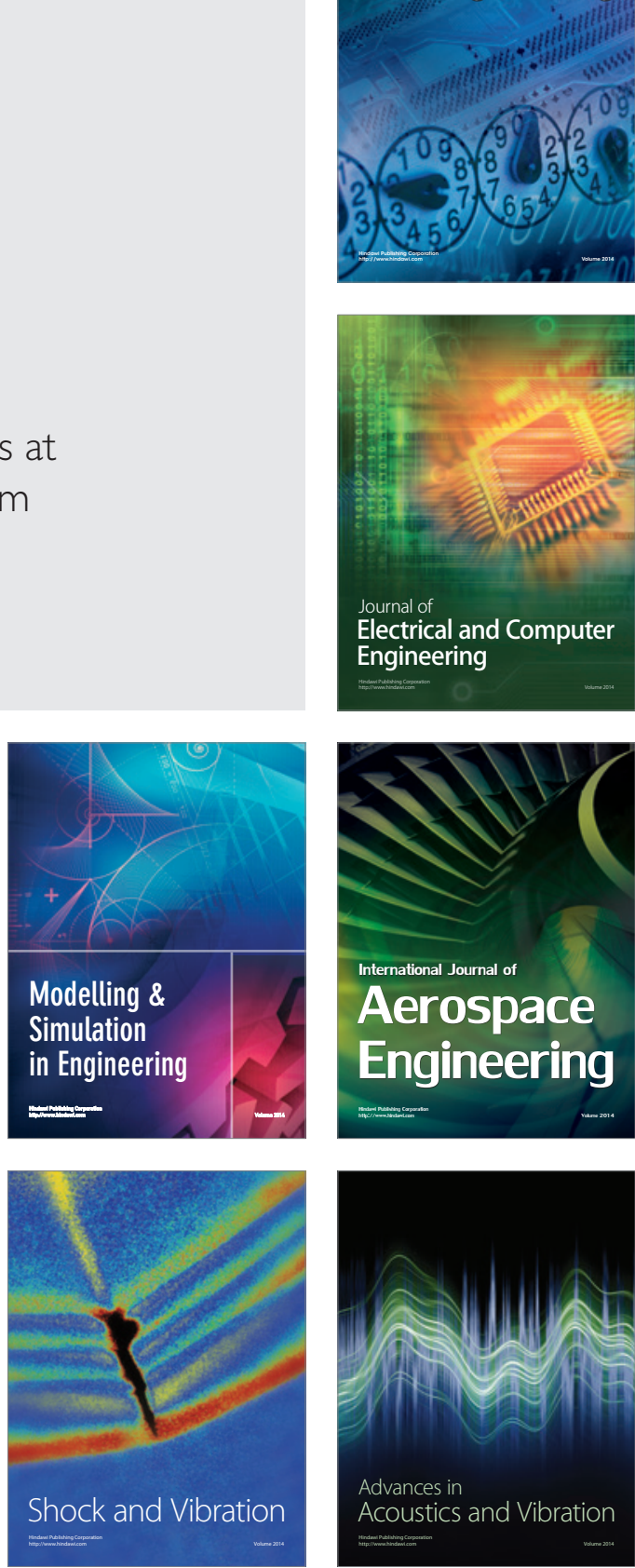